\title{
Measuring and monitoring soil organic carbon stocks in agricultural lands for climate mitigation
}

\author{
Richard T Conant ${ }^{1,2^{*}}$, Stephen M Ogle ${ }^{1}$, Eldor A Paul ${ }^{1,3}$, and Keith Paustian ${ }^{1,3}$
}

Policies that encourage greenhouse-gas emitters to mitigate emissions through terrestrial carbon (C) offsets - C sequestration in soils or biomass - will promote practices that reduce erosion and build soil fertility, while fostering adaptation to climate change, agricultural development, and rehabilitation of degraded soils. However, none of these benefits will be possible until changes in C stocks can be documented accurately and cost-effectively. This is particularly challenging when dealing with changes in soil organic C (SOC) stocks. Precise methods for measuring $C$ in soil samples are well established, but spatial variability in the factors that determine SOC stocks makes it difficult to document change. Widespread interest in the benefits of SOC sequestration has brought this issue to the fore in the development of US and international climate policy. Here, we review the challenges to documenting changes in SOC stocks, how policy decisions influence offset documentation requirements, and the benefits and drawbacks of different sampling strategies and extrapolation methods.

Front Ecol Environ 2011; 9(3): 169-173, doi:10.1890/090153 (published online 8 Jun 2010)

$\mathrm{T}_{\mathrm{in}}$ errestrial carbon (C) offsets - sequestration of organic C in soils or biomass brought about by intentional changes in land management - offer the possibility of reducing the concentration of atmospheric carbon dioxide $\left(\mathrm{CO}_{2}\right)$, offsetting emissions from other sectors. However, their inclusion in US climate and international $\mathrm{C}$ policy is controversial. Forest growth and agricultural soil organic $\mathrm{C}$ (SOC) sequestration currently offset about $13 \%$ of US fossil-fuel emissions (US EPA 2008) and, given policies to promote adoption of land-management practices that sequester $\mathrm{C}$, that percentage could increase in the future (Pacala et al. 2007). In agri-

\section{In a nutshell:}

- Dependable methods for measuring terrestrial carbon offsets are critically important for developing a legitimate terrestrial carbon offset market

- Existing methods for quantifying soil organic carbon (SOC) concentration in samples are well established and have a high analytical precision

- Quantifying changes in SOC stocks relies on a set of measurements that are extrapolated in various ways to represent a larger geographic area

- The main challenge in documenting plot-level changes in SOC stocks is in designing an efficient, cost-effective sampling and SOC stock estimation system

- The most dependable SOC stock estimation systems will be those that are accurate, flexible, and inexpensive, and that can most easily integrate new data and knowledge

\footnotetext{
${ }^{1}$ Natural Resource Ecology Laboratory, Colorado State University, Fort Collins, CO *(conant@nrel.colostate.edu); ${ }^{2}$ School of Global Environmental Sustainability, Colorado State University, Fort Collins, CO; ${ }^{3}$ Department of Soil and Crop Sciences, Colorado State University, Fort Collins, CO
}

cultural lands, terrestrial SOC offsets can be realized relatively quickly, through existing technology (Figure 1); in many cases, such options could cost less than the expense associated with direct emission reductions, providing flexibility in meeting emission targets or restrictions (Smith et al. 2007). However, the Kyoto Protocol's Clean Development Mechanism has demonstrated that in the absence of well-formulated regulations on allowable offsets, billions of US dollars can be spent obtaining offsets with doubtful claims of actual greenhouse-gas reductions (Wara 2007). The debate about the legitimacy of terrestrial offsets versus their utility pits public interest groups, who demand genuine emission reductions, against the sectors likely to face emission caps, who desire a variety of options for achieving emission reduction targets at the lowest possible cost.

Policies that permit offsets have attempted to resolve this tension by restricting the size of the offset market. For example, the American Clean Energy and Security Act of 2009 limits market participation of terrestrial C offsets to two billion tons of $\mathrm{CO}_{2}$ equivalents - ie emissions of other greenhouse gases, such as methane and nitrous oxide, can be converted to $\mathrm{CO}_{2}$ equivalents by accounting for differences in radiative forcing and lifetime in the atmosphere (these calculations allow comparability of the impacts of different greenhouse gases, or emission reduction strategies). Restrictions can also limit the range of allowable land-management practices (as specified in the Kyoto Protocol), may allow some greenhouse gases but not others, and can stipulate verification procedures that reduce participation. However, limiting the breadth and diversity of market participants alone will not necessarily enhance the reliability of offsets.

Robust, transparent, and accurate, yet inexpensive, methods for verifying terrestrial $\mathrm{C}$ offsets are critically important 


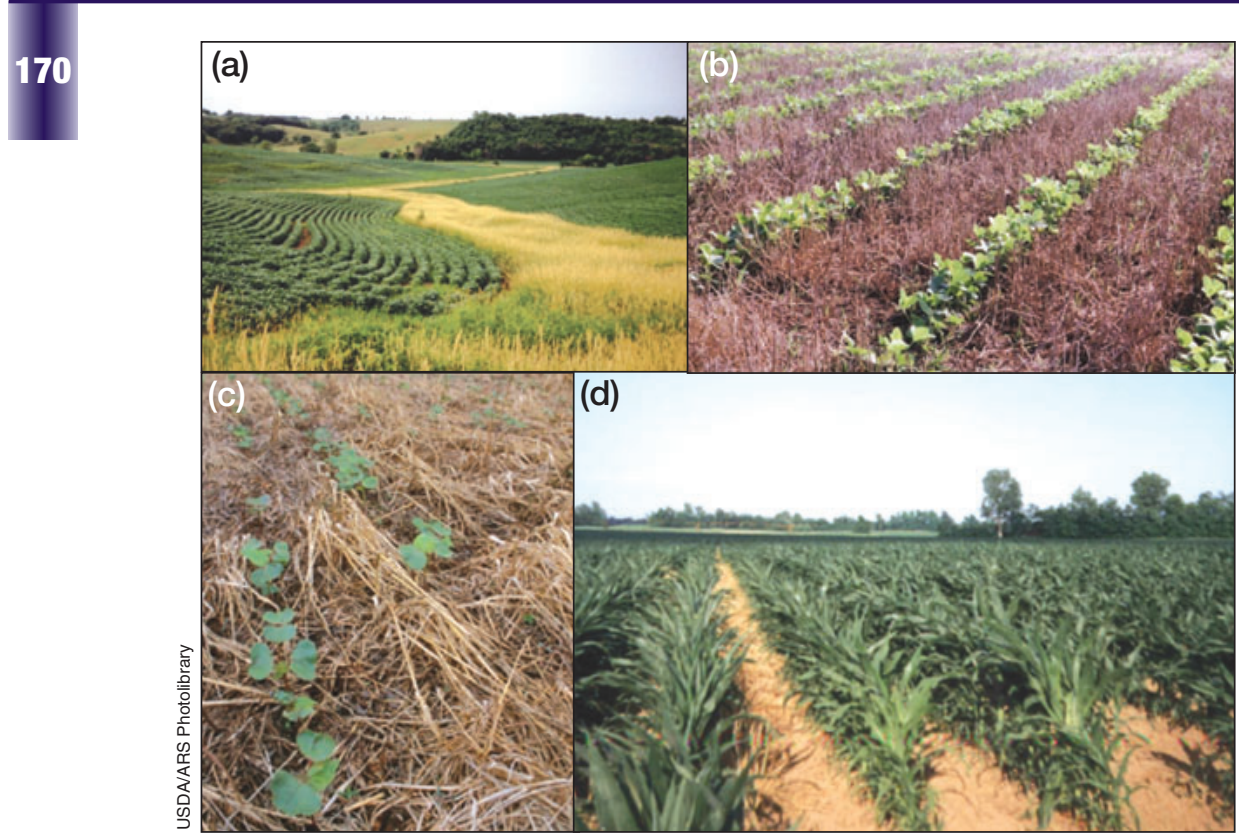

Figure 1. Practices that increase C uptake or decrease C losses - such as (a) conservation buffers, (b) conservation tillage, (c) cover crops, and (d) crop rotations that reduce fallow frequency - can build $\mathrm{C}$ stocks, sequestering $\mathrm{CO}_{2}$ from the atmosphere.

for developing a broad - and legitimate - terrestrial offset market. Verification methods that accurately attribute net emission reduction or sequestration to a parcel of land or a practice have not yet been agreed upon. Methods of establishing baselines and their associated uncertainty and that account for additionality, leakage, and permanence (WebPanel 1) are necessary, but remain unresolved. Here, we review the requirements for quantifying agricultural SOC offsets, the challenges to verifying those $\mathrm{C}$ offsets, and both the benefits and the limitations of various approaches.

\section{Different approaches to measurement and monitoring}

\section{Field sampling of changes in C stocks}

Methods for analyzing the SOC concentration of a given sample are well-established and easily carried out, with high precision and negligible analytical error (Nelson and Sommers 1996). However, SOC stocks vary as a function of soil texture, landscape position, drainage, plant productivity, and soil density, all of which vary spatially and contribute to the spatial variation in SOC stocks, making it difficult to quantify changes in SOC stocks over time (Table 1; Cambardella et al. 1994; Robertson et al. 1997; VandenBygaart 2006). Two samples taken from different areas in the same field are likely to have different SOC concentrations; accounting for this spatial variability is essential, otherwise a considerable degree of uncertainty is introduced into SOC stock estimates (Figures 2 and 3). Furthermore, all of the processes that lead to $\mathrm{C}$ sequestration in agricultural soils reduced tillage, enhanced residue inputs, fallow reduction, cover crops, etc - do so non-uniformly across fields and land- scapes. In quantifying agricultural SOC offsets, the challenge is further compounded by the fact that SOC changes will be small relative to changes in the large $\mathrm{C}$ stocks typically found in most soils (ie a low signal-to-noise ratio). Sampling error can therefore be large and "the cumulative effects of managing small net sinks to mitigate fossil-fuel emissions will have to be understood, analyzed, monitored, and evaluated in the context of larger, highly variable, and uncertain sources and sinks in the natural cycle" (Birdsey et al. 2007).

The main difficulty in documenting plotlevel changes in SOC stocks is not with measuring the SOC, but rather in designing an efficient, cost-effective sampling and SOC stock estimation system. All field sampling methods for verifying changes in SOC stocks rely on a set of measurements that are extrapolated to represent a given geographic area. Classical and geospatial sampling are based on approaches commonly used in agronomic and ecological experiments and analyses that employ wellestablished, highly accurate analytical methods (Wiley and Chameides 2007). Both can be used to assess uncertainty by collecting multiple replicates within fields or across regions (Conant and Paustian 2002) and both can enable efficient resampling by incorporating information on SOC variation (Conant et al. 2003; Mooney et al. 2007; Homann et al. 2008). But such intensive sampling is time consuming and expensive. Given high rates of SOC sequestration, relatively low initial amounts of SOC, and modest spatial variability, the standard approach for a project - sampling and then future resampling of soil cores - would still require collection and analysis of dozens of soil samples to detect changes within a given field over a 5-10 year period (Conant and Paustian 2002; Yang et al. 2008). Quantifying SOC changes at national or regional scales requires much more modest sampling densities (Makipaa et al. 2008); however, such sampling precludes attributing change in SOC stocks to a particular practice or plot of land and is unlikely to require long intervals between sampling before changes in SOC stocks can be detected (Saby et al. 2008). Similarly, aggregating across many fields that share a common change in management could reduce the number of samples required to quantify changes in SOC stocks, but at the expense of distributing $\mathrm{C}$ credits evenly across the aggregated parties in proportion to the amount of $\mathrm{C}$ sequestered.

New measurement techniques - such as a near infrared probe mounted on an implement pulled through the soil (Christy 2008) or gamma-ray spectroscopy based on inelastic neutron scattering - may enable field-wide measurements of SOC stocks, either directly (Wielopolski et al. 2008) or indirectly, through observation of SOC-stock covariates (Simbahan et al. 2006). However, these technologies currently require extensive site-specific instrument calibration or evaluation of covariates, involving tradi- 


\begin{tabular}{|c|c|c|c|}
\hline Approach & Sampling required & Benefits & Drawbacks \\
\hline $\begin{array}{l}\text { Model or practice- } \\
\text { based estimation }\end{array}$ & None & $\begin{array}{l}\text { Inexpensive, flexible; able to employ } \\
\text { a variety of methods for baselines, } \\
\text { additionality, and leakage }\end{array}$ & $\begin{array}{l}\text { Limited applicability; high, often } \\
\text { unquantified, uncertainty }\end{array}$ \\
\hline Statistical upscaling & Intensive sampling & $\begin{array}{l}\text { Direct; known and controllable } \\
\text { uncertainty; standard practice }\end{array}$ & $\begin{array}{l}\text { Expensive, labor intensive; substantial } \\
\text { challenges when accounting for baselines, } \\
\text { additionality, and leakage }\end{array}$ \\
\hline $\begin{array}{l}\text { Geostatistical } \\
\text { upscaling }\end{array}$ & $\begin{array}{l}\text { Intensive initial sampling; } \\
\text { intensive resampling of } \\
\text { covariates }\end{array}$ & $\begin{array}{l}\text { Low cost; spatial maps of SOC } \\
\text { stocks; whole-field assessment }\end{array}$ & $\begin{array}{l}\text { Labor/cost intensive; requires assessment } \\
\text { of covariates; substantial challenges when } \\
\text { accounting for baselines, additionality, } \\
\text { and leakage }\end{array}$ \\
\hline Whole-field sampling & Intensive for calibration & $\begin{array}{l}\text { Comprehensive, whole-field sample; } \\
\text { potentially low labor/low cost }\end{array}$ & $\begin{array}{l}\text { Requires intensive calibration; substantial } \\
\text { challenges when accounting for baselines, } \\
\text { additionality, and leakage }\end{array}$ \\
\hline $\begin{array}{l}\text { Net ecosystem } \\
\text { exchange }\end{array}$ & $\begin{array}{l}\text { Long-term, continuous } \\
\mathrm{CO}_{2} \text { flux measurements }\end{array}$ & Comprehensive, whole-field sample & $\begin{array}{l}\text { Expensive, labor-intensive, long-term } \\
\text { monitoring; uncertainties associated with } \\
\text { poor energy-budget closure; limited ability } \\
\text { to discern differences due to management; } \\
\text { substantial year-to-year variability, such that } \\
\text { different time scales of observation can } \\
\text { confound results }\end{array}$ \\
\hline $\begin{array}{l}\text { Combined modeling } \\
\text { and measurement }\end{array}$ & $\begin{array}{l}\text { Measurements for model } \\
\text { uncertainty estimation }\end{array}$ & $\begin{array}{l}\text { Integrates wide suite of observations; } \\
\text { limited soil sampling required; } \\
\text { extrapolation based on established } \\
\text { control mechanisms; able to employ } \\
\text { a variety of methods for baselines, } \\
\text { additionality, and leakage; robust } \\
\text { system can guide future sampling }\end{array}$ & $\begin{array}{l}\text { Models not always easy to parameterize } \\
\text { or run; models not parameterized for all } \\
\text { systems of interest; variety of simulation } \\
\text { models available }\end{array}$ \\
\hline
\end{tabular}

tional destructive sampling and laboratory analyses. In the future, such approaches may provide a potentially low-cost method for comprehensive sampling, but much additional research is needed before these approaches are ready for wide-scale implementation.

\section{Practice-based estimates of SOC sequestration}

One common approach for assessing changes in SOC stocks is to use information synthesized from previously published studies on how changes in management practices affect SOC stocks. Markets (such as the Chicago Climate Exchange, www.chicagoclimatex.com) and direct offset trades in the US (such as the Pacific Northwest Direct Seed Association's Carbon Offset Project) currently rely on such practice-based approaches. Offsets can be verified by monitoring agronomic practices (eg monitoring no-tillage by surveying residue coverage on the soil surface). Such verification is already established for other conservation programs and can be relatively inexpensive. Syntheses of existing field experiments (eg Ogle et al. 2005) provide empirical estimates of the average SOC change for a particular practice within a broad region. However, because published studies of land-management impacts on SOC stocks are so uncommon and site-specific, the utilization of those studies to estimate sequestration rates in a given region - for a specific farm or group of farms - will lead to substantial uncertainty. This uncertainty is difficult to quantify through statistical methods with limited data. Moreover, the sequestration rates are typically based on relative changes in SOC stocks, which could differ from the actual rates if other environmental drivers (eg climate change) are also contributing to changes in SOC stocks. If uncertainty is high, permitted SOC offsets may be substantially discounted relative to estimated $\mathrm{C}$ sequestered, in order to limit the risk that the offsets do not represent realistic reductions in $\mathrm{CO}_{2}$ emissions to the atmosphere (eg VCS 2008). Another limitation of a broad practice-based approach is that it is economically inefficient (Antle et al. 2003). Because of heterogeneity in the response of soils to specific management practices (resulting from differences in soils, climate conditions, land-use history, etc), broadly based payments by practice will overcompensate poor performance and undercompensate good performance (thereby reducing the incentive to participate). Thus, even if the practice-based credit was an accurate estimate for average performance within the region, the actual benefits achieved would be overestimated, and this inefficiency would increase as a function of the degree of spatial heterogeneity in soil response (Antle et al. 2003). An estimation system that can account for more of the local variability in soil responses to a particular manage- 


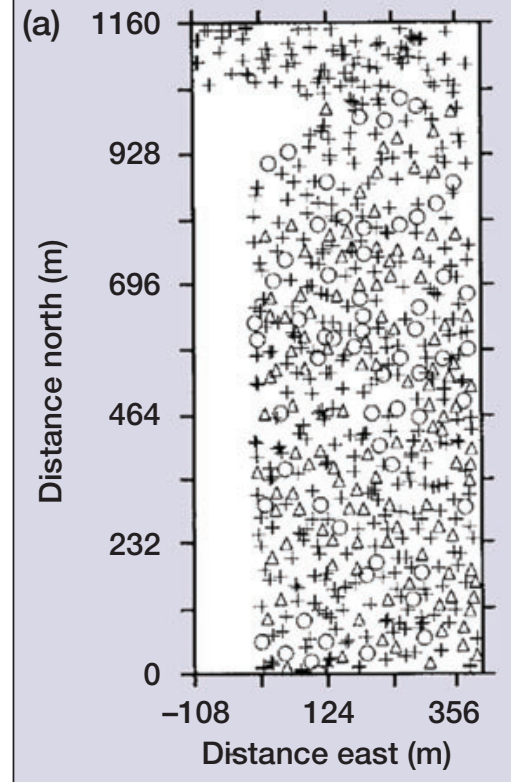

(b)

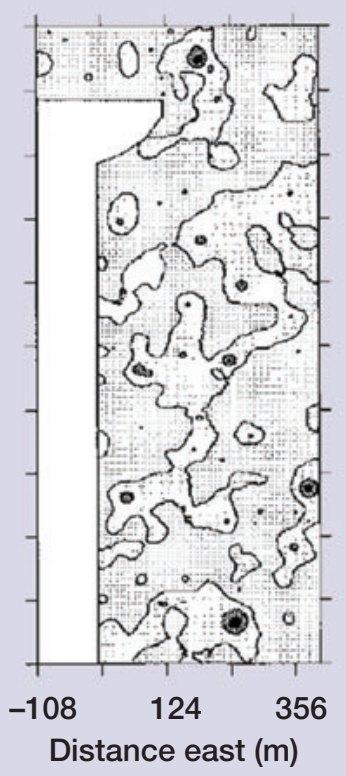

Figure 2. High sampling densities (panel [a]; samples were taken at all "+" locations and some "o" locations) show substantial spatial variation in SOC stocks (b) across a field with uniform appearance. In this case, SOC concentrations range between $0.85 \%$ and $1.93 \%$. Reprinted from Robertson et al. (1997). Distance east $=$ east-west distance from a fixed point .

ment practice will increase the economic efficiency of the mitigation policy and provide a better estimate of the actual mitigation-related benefits achieved.

\section{Combining measurement with mechanistic modeling}

Researchers can quantify terrestrial SOC offsets using a mechanistic ecosystem model. Such an approach is widely used for reporting national SOC inventories under the UN Framework Convention on Climate Change. For example, the Century model (Parton et al. 1987) is used to estimate

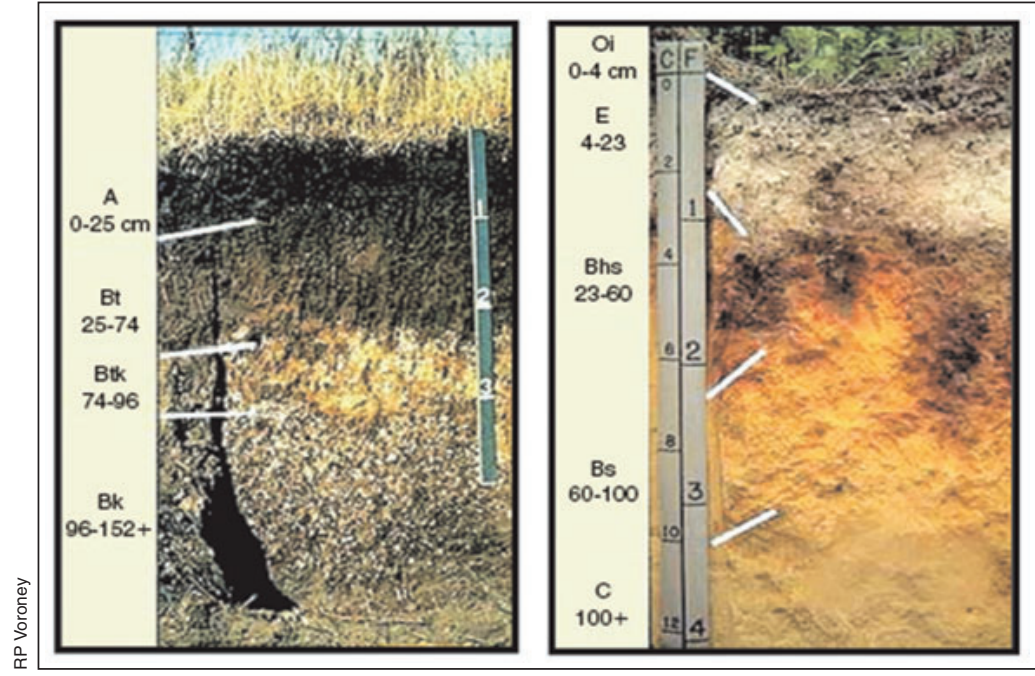

Figure 3. Soil organic matter concentrations are clearly reflected by variations in soil color, but accurately quantifying changes in SOC stocks is difficult. Spatial variation that is not apparent from the surface, as seen here, increases the variation between samples, reducing the ability to detect differences.
SOC stocks in the US and Canadian national inventories. This approach has also been used to document voluntary SOC offsets through the US Energy Information Administration's 1605(b) program (eg Paustian et al. 2009). Coupled with published information on management impacts, systems such as this are capable of estimating uncertainty associated with SOC sequestration estimates (Ogle et al. 2010). Quantification systems based on mechanistic models are inherently flexible, because they are able to represent a wide range of distinctive climate and soil management conditions. They can also be designed to be run with a small set of driving data, making them easy to use, and updated as new information becomes available (Jones et al. 2004).

A dynamic database, one that is regularly populated with the most recent terrestrial SOC offset data, could integrate field measurements with state-of-the-art knowledge about ecosystem function and enable up-to-date calculations of model uncertainty estimates through statistical methods similar to those described by Ogle et al. (2007). Such a system would benefit from a mechanistic modeling framework that captures process-based understanding of $\mathrm{C}$ dynamics, and an underlying suite of independent observations to verify model results. Combining measurement of SOC with models would have several distinct benefits not possible through modeling or measurement alone. Carbon exchange accounting rules that discount or withhold credits in reserve to account for uncertainty - some carbon exchange rules, like those developed by the Voluntary Carbon Standard (www.v-c-s.org), require that a portion of the estimated SOC sequestration be held in reserve to ensure against non-compliance or reversals (eg through fire) - could use uncertainty derived from the model analysis associated with a particular offset activity to determine reserve requirements. Combining measurement and modeling would have the flexibility of a model-based approach - being able to account for all types of terrestrial offsets, unlike relying entirely on direct measurements, which is likely to have gaps. A combined modeling-measurement approach would be reliable, because the associated uncertainty is determined from on-the-ground observations. As a system, such a coupled modelingmeasurement approach would be robust, because it could be continually updated with new sample data and could be used to direct sampling toward those areas where uncertainty is largest relative to offset activity. Combining modeling and measurement could also potentially encourage more innovation by agricultural producers, because new measurements could be incorporated from the latest management options. This would allow all producers to receive credit from the latest 
innovations based on modeled data without necessarily requiring new measurements on each farm. Finally, a combined system could exploit published information on how other factors (such as global change, widespread land-use changes, etc) affect SOC stocks both on- and offsite, to account for shifting baselines, additionality, and leakage.

\section{Conclusions}

The variety of approaches proposed to quantify agricultural offsets is a testament to the inherent difficulties in estimating changes in SOC stocks over time - including spatial variation, slow overall turnover times, small changes relative to SOC stocks, and the intangibility of SOC for scientists, policy makers, and/or natural resource managers who are unfamiliar with soil science or related fields. These challenges contribute to objections to mitigation policies that include agricultural offsets for $\mathrm{C}$ sequestration in soils. In the future, these challenges may limit the role of agricultural offsets in reducing greenhouse-gas emissions, despite the fact that SOC stocks have been accurately measured for decades (Nelson and Sommers 1996) and that the cost of such measurements may represent only a small fraction of project expenses (Mooney et al. 2004). Developing a set of terrestrial SOC offset standards from this suite of approaches is crucial for widespread acceptance and implementation of reliable, accurate, and credible agricultural C offsets that can mitigate greenhouse-gas emissions and reduce the influence of anthropogenic activities on climate.

\section{Acknowledgements}

This work was supported by a grant from the Robertson Foundation, the USDA/CSREES Carbon Cycle Science Program (Agreement \#2005-35615-15223), the NASA Applied Science Program (Agreement \#NNG05GL07G), and the US Department of Energy (Grant \#DE-FG02-04ER63890).

\section{References}

Antle JM, Capalbo SM, Mooney S, et al. 2003. Spatial heterogeneity, contract design, and the efficiency of carbon sequestration policies for agriculture. J Environ Econ Manag 46: 231-50.

Birdsey RA, Jenkins JC, Johnston M, et al. 2007. North American forests. In: King AW, Dilling L, Zimmerman GP, et al. (Eds). State of the carbon cycle report. Washington, DC: US Department of Energy.

Cambardella CA, Moorman TB, Novak JM, et al. 1994. Field-scale variability of soil properties in central Iowa soils. Soil Sci Soc Am J 58: 1501-11.

Christy CD. 2008. Real-time measurement of soil attributes using on-the-go near infrared reflectance spectroscopy. Comput Electron Agric 61: 10-19.

Conant RT and Paustian K. 2002. Spatial variability of soil organic carbon: implications for detecting change at different scales. Environ Pollut 116: 127-35.

Conant RT, Smith GR, and Paustian K. 2003. Spatial variability of soil carbon in forested and cultivated sites: implications for change detection. J Environ Qual 32: 278-86.

Homann PS, Bormann BT, Boyle JR, et al. 2008. Soil C and N minimum detectable changes and treatment differences in a multi- treatment forest experiment. Forest Ecol Manag 255: 1724-34.

Jones JW, Graham WD, Wallach D, et al. 2004. Estimating soil carbon levels using an Ensemble Kalman filter. T Asae 47: 331-39.

Makipaa R, Hakkinen M, Muukkonen P, et al. 2008. The costs of monitoring changes in forest soil carbon stocks. Boreal Environ Res 13: 120-30.

Mooney S, Antle J, Capalbo S, et al. 2004. Design and costs of a measurement protocol for trades in soil carbon credits. Can J Agr Econ 52: 257-87.

Mooney S, Gerow K, Antle J, et al. 2007. Reducing standard errors by incorporating spatial autocorrelation into a measurement scheme for soil carbon credits. Climatic Change 80: 55-72.

Nelson DW and Sommers LE. 1996. Total carbon, organic carbon, and organic matter. In: Sparks DL (Ed). Methods of soil analysis. Part 3: chemical methods. Madison, WI: Soil Science Society of America.

Ogle SM, Breidt FJ, Easter M, et al. 2010. Scale and uncertainty in modeled SOC stock changes for US croplands using a processbased model. Glob Change Biol 16: 810-22.

Ogle SM, Breidt FJ, Easter M, et al. 2007. An empirically based approach for estimating uncertainty associated with modeling carbon sequestration in soils. Ecol Model 205: 453-63.

Ogle SM, Breidt FJ, and Paustian K. 2005. Agricultural management impacts on soil organic carbon storage under moist and dry climatic conditions of temperate and tropical regions. Biogeochemistry 72: 87-121.

Pacala S, Birdsey RA, Bridgham S, et al. 2007. State of the carbon cycle: the North America carbon budget past and present. Washington, DC: US Department of Energy.

Parton WJ, Schimel DS, Cole CV, et al. 1987. Analysis of factors controlling soil organic matter levels in Great Plains grasslands. Soil Sci Soc Am J 51: 1173-79.

Paustian K, Brenner J, Easter M, et al. 2009. Counting carbon on the farm: reaping the benefits of carbon offset programs. J Soil Water Conserv 64: 36A-40A.

Robertson GP, Klingensmith KM, Klug MJ, et al. 1997. Soil resources, microbial activity, and primary production across an agricultural ecosystem. Ecol Appl 7: 158-70.

Saby NPA, Bellamy PH, Morvan X, et al. 2008. Will European soilmonitoring networks be able to detect changes in topsoil organic carbon content? Glob Change Biol 14: 2432-42.

Simbahan GC, Dobermann A, Goovaerts P, et al. 2006. Fine-resolution mapping of soil organic carbon based on multivariate secondary data. Geoderma 132: 471-89.

Smith P, Martino D, Cai ZC, et al. 2007. Policy and technological constraints to implementation of greenhouse gas mitigation options in agriculture. Agr Ecosyst Environ 118: 6-28.

US EPA (US Environmental Protection Agency). 2008. Inventory of US greenhouse gas emissions and sinks: 1990-2006. Washington, DC: US EPA. http://yosemite.epa.gov/oar/globalwar ming.nsf/content/ResourceCenterPublicationsGHGEmissions. htmlsoer. Viewed 20 Jan 2010.

VandenBygaart AJ. 2006. Monitoring soil organic carbon stock changes in agricultural landscapes: issues and a proposed approach. Can J Soil Sci 86: 451-63.

VCS (Voluntary Carbon Standard). 2008. Voluntary Carbon Standard. www.v-c-s.org/docs/Voluntary\%20Carbon\%20Standard \%202007_1.pdf. Viewed 19 Jan 2010.

Wara M. 2007. Is the global carbon market working? Nature 445: 595-96.

Wielopolski L, Hendrey G, Johnsen KH, et al. 2008. Nondestructive system for analyzing carbon in soil. Soil Sci Soc Am J 72: 1269-77.

Wiley Z and Chameides W. 2007. Harnessing farms and forests in the low-carbon economy. Durham, NC: Duke University Press.

Yang XM, Drury CF, Wander MM, et al. 2008. Evaluating the effect of tillage on carbon sequestration using the minimum detectable difference concept. Pedosphere 18: 421-30. 